\title{
Modelagem Computacional de uma LISN APlicada ao SETOR Automotivo
}

\author{
Luis Alves Correia Filho ${ }^{1}$, Kenedy Marconi Geraldo dos Santos ${ }^{1,2}$, Caio Luminatti Andrade ${ }^{3}$, \\ Bruno dos Santos de Matos ${ }^{1}$ e Leandro Machado Oliveira ${ }^{1}$ \\ ${ }^{1}$ Instituto Federal da Bahia - IFBA, ${ }^{2}$ Universidade Federal da Bahia - UFBA e \\ ${ }^{3}$ Serviço Nacional de Aprendizagem Industrial - SENAI CIMATEC
}

E-mails: 1uis.acf10@gmail.com, kenedymarconi@gmail.com, luminatticaio@yahoo.com.br, bruno.dmatos@hotmail.com, leandrooliveirabdo@,gmail.com

\section{RESUMO}

O ambiente automotivo necessita de soluções com baixo custo, práticas e eficientes para a área de compatibilidade eletromagnética (EMC), sendo necessário realizar os ensaios com rapidez e confiabilidade. Uma das formas de atender a demanda da indústria na atualidade é utilizar a modelagem computacional para obter resultados rápidos e objetivos. A simulação computacional é baseada na utilização de certas técnicas matemáticas, análise numérica, cálculo com matrizes etc. As quais são usadas em softwares iterativos de elevado desempenho. Uma LISN (Line Impedance Stabilization Network) é um equipamento utilizado principalmente para isolar o ruído da fonte de alimentação e fornecer uma porta com impedância estável para o equipamento de medição, sendo necessária para a realização dos ensaios de emissões eletromagnéticas conduzidas e irradiadas. Através destas medições é possível verificar se o DUT (Device Under Test) atende as solicitações das normativas vigentes. $\mathrm{O}$ artigo irá abordar a modelagem computacional de uma LISN. O objetivo principal é mostrar o seu comportamento na faixa de frequência de $150 \mathrm{kHz}$ a $30 \mathrm{MHz}$.

\section{INTRODUÇÃO}

A realização dos desenvolvimentos na ótica de EMC é um processo demorado, principalmente devido às inúmeras reprovações que o componente pode apresentar por não atender as normativas vigentes, e poderá ocasionar despesas financeiras elevadas no processo de desenvolvimento do produto. Infelizmente, estes ensaios são muitas vezes conduzidos no final de um estágio de desenvolvimento, onde corrigir um problema de EMC pode ser ainda mais difícil e caro [1].

Métodos analíticos e numéricos validados têm o potencial de tornarem-se cada vez mais importantes, como um processo para determinar os efeitos de campos externos sobre sistemas eletrônicos de um carro, ou antecipando como as emissões eletromagnéticas irão se desenvolver [2].

Em ensaios de EMC são necessários muitos equipamentos de elevado custo e alta precisão que demandam manutenção, calibração, além da necessidade de um ambiente específico 
isolado de interferências eletromagnéticas externas como uma Câmara Blindada Semianecóica.

Esse artigo trata-se da modelagem computacional de uma LISN, um equipamento utilizado para ensaio de emissões conduzidas, onde são apresentadas curvas comparativas entre a LISN computacional proposta e a LISN comercial. Também é realizada uma comparação de alguns parâmetros simulados com os limites especificados pelas normas CISPR16 e CISPR25.

No decorrer do trabalho são apresentados os resultados da simulação dos parâmetros a seguir:

- Impedância no domínio da frequência vista dos terminais do DUT;

- Impedância no domínio da frequência vista nos terminais do Medidor;

- Transmissão do ruído de alta frequência gerado pelo DUT que será medido pelo analisador de espectro ou receptor;

\section{PARÂMETROS E FUNCIONAMENTO DE UMA LISN IDEAL}

Uma LISN (Line Impedance Stabilization Network) é um equipamento utilizado em ensaios de emissões eletromagnéticas conduzidas e apresenta dois objetivos principais são eles:

1) Apresentar uma impedância constante para a alimentação dentro da faixa de frequência especificada;

2) Bloquear as emissões conduzidas que não se referem aos distúrbios gerados pelo DUT (Device Under Test) [3].

O circuito básico que envolve a LISN mostra dois comportamentos distintos: um para sinais de baixa frequência e outro para sinais de alta frequência. Para sinais de baixa frequência, referente ao circuito de alimentação, os capacitores no circuito funcionam como um circuito aberto entre a fonte de alimentação e o aparelho de medição (Analisador de Espectro ou Receptor de RF). O indutor, para baixa frequência, funciona com um fio condutor entre o sinal de alimentação da fonte de tensão e o DUT, o que permite a alimentação do equipamento sob ensaio. Para os ruídos em alta frequência que serão medidos, a impedância dos capacitores é muito baixa havendo assim pouca ou nenhuma atenuação, possibilitando uma medição mais exata das emissões referentes ao ruído conduzido [4].

Outro objetivo da LISN é apresentar uma impedância constante e que esta seja igual à impedância de saída do medidor. Diante deste cenário irá ocorrer a máxima transferência de potência e o ruído não irá sofrer atenuação [2].

\section{DESCRIÇÃO DO PROBLEMA}

O objetivo da modelagem para a área de EMC Automotiva é tentar antecipar futuros problemas no processo de desenvolvimento do produto [1] e [2].

Neste trabalho a modelagem foi realizada para trabalhar em frequências que variam de 150 $\mathrm{KHz}$ até $30 \mathrm{MHz}$, pelo fato de apresentar características próximas de uma LISN real.

A fonte de tensão para os equipamentos automotivos é uma bateria de 12 volts corrente continua, ou seja, a frequência é zero e por isso não há ruídos provenientes da fonte de tensão para o DUT. 
A modelagem computacional foi estudada em uma faixa de frequência que varia de $150 \mathrm{kHz}$ até aproximadamente $30 \mathrm{MHz}$.

\section{SIMULAÇÃO COMPUTACIONAL}

\subsection{Recursos Utilizados}

Para a simulação foi utilizado o software Matlab (Simulink/Simscape) para traçar os gráficos e implementar as equações [5].

Foram utilizadas as especificações técnicas de uma LISN comercial Schwarzbeck NNBM 8124 mostrada na Figura 1. A principal aplicação dessa LISN é na medição de ruídos conduzidos em veículos, aeronaves e em navios na faixa HF-VHF (0.1-150 MHz) [6].

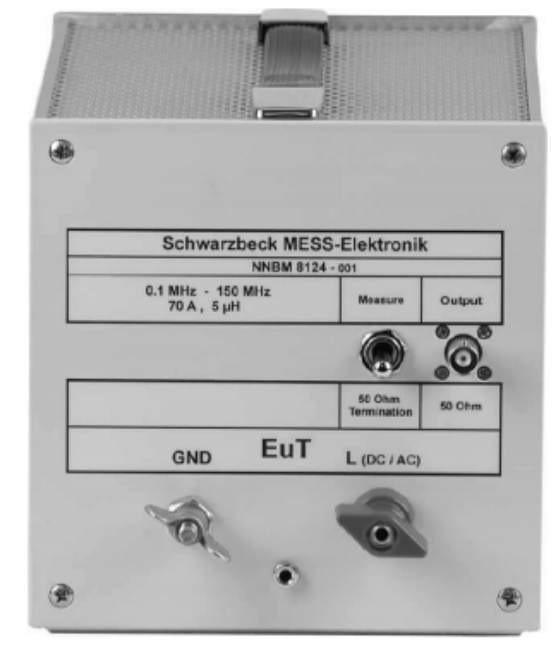

Figura 1: LISN Scharzbeck NNBM 8124 [6]

\subsection{Simulação do Comportamento da Impedância no Domínio da Frequência Vista dos Terminais do DUT}

Como foi citado anteriormente, a LISN tem o objetivo de fornecer uma impedância predominantemente constante tanto com relação aos terminais do DUT quanto com relação ao medidor, que pode ser este um analisador de espectro ou receptor de RF [3].

Para verificar essa propriedade da LISN, foi realizada uma simulação do comportamento da impedância no domínio da frequência, ou seja, LISN modelada computacionalmente versus a comercial.

Para determinar a impedância vista pelo DUT, os terminais da fonte foram ligados entre si e conforme o arranjo apresentado na Figura 2: 


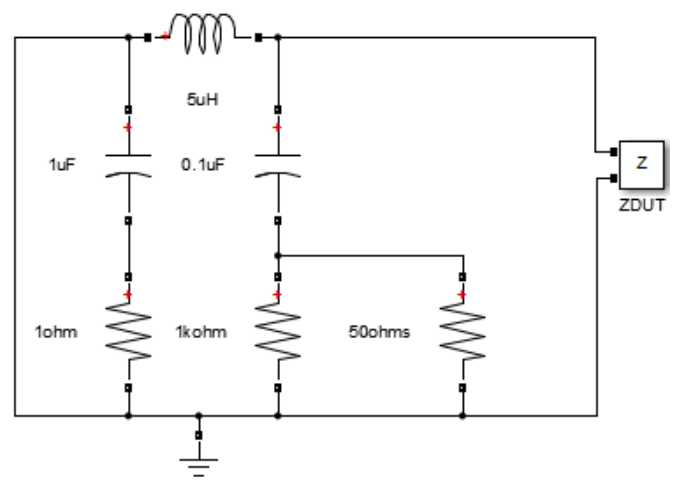

Figura 2: Simulação do comportamento da impedância no domínio da frequência vista dos terminais do DUT

Em paralelo com o resistor de $1 \mathrm{k} \Omega$, foi colocado um de $50 \Omega$, simulando a impedância de entrada do equipamento de medição (analisador de espectro ou receptor de RF).

Os gráficos obtidos a partir do medidor de impedância (ZDUT) foram comparados com a LISN comercial Schwarzbeck NNBM 8124 e os limites das normas CISPR 16 e CISPR 25. Os resultados obtidos para a magnitude e a fase da impedância estão nas Figuras 3 e 4 a seguir:

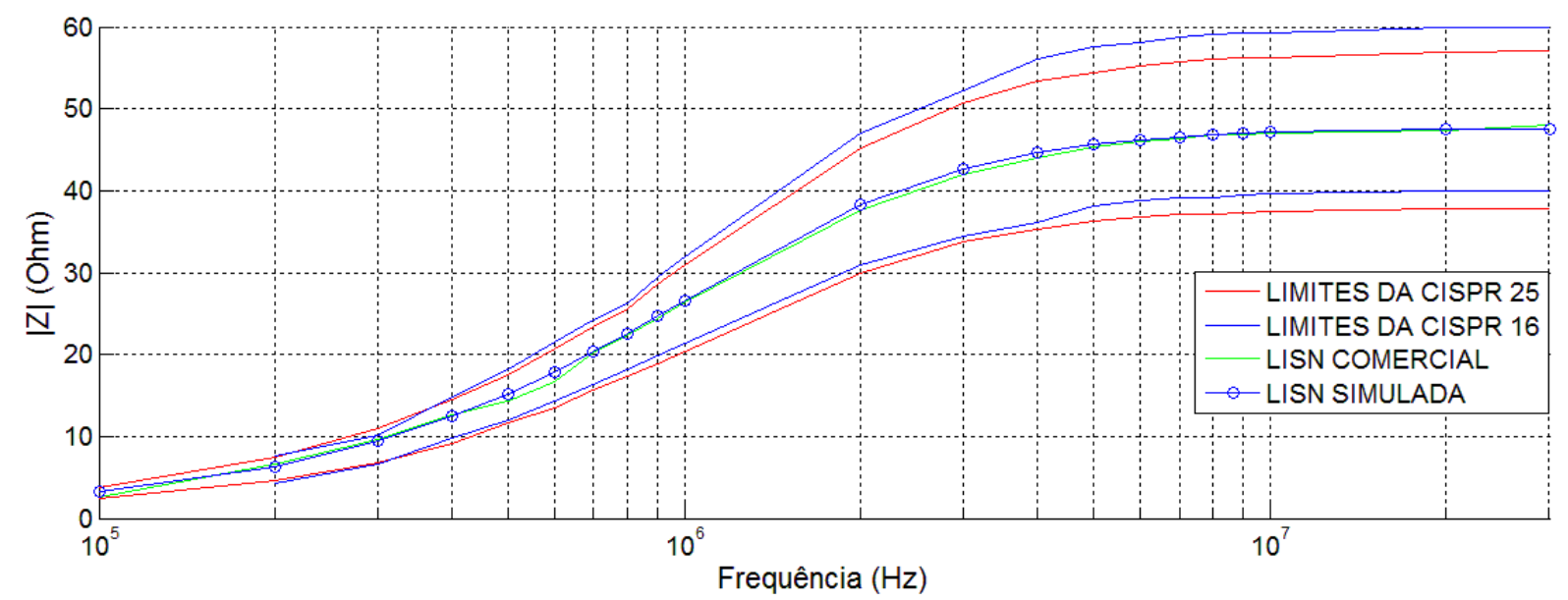

Figura 3: Gráfico da magnitude da impedância vista dos terminais do DUT (Device Under Test).

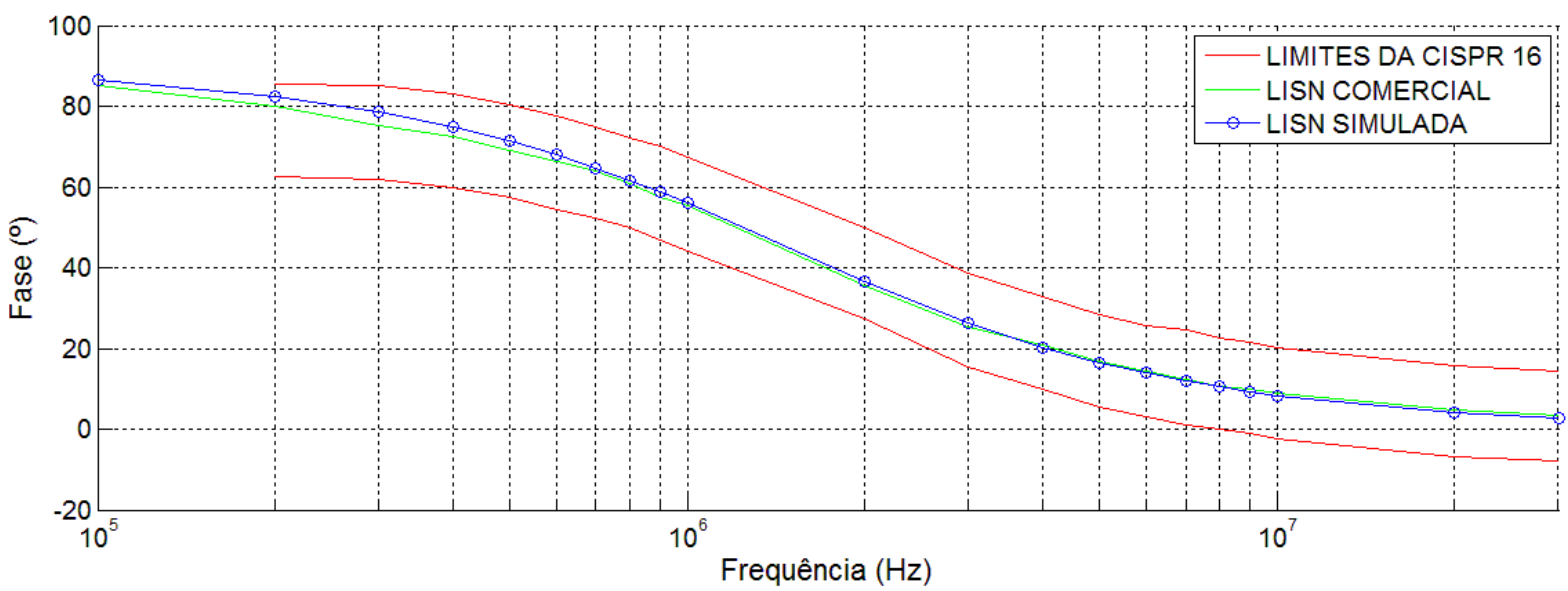

Figura 4: Gráfico da fase da impedância vista dos terminais do DUT (Device Under Test). 


\subsection{Simulação do Comportamento da Impedância no Domínio da Frequência Vista dos Terminais do Medidor}

A fim de que o sinal de alta frequência gerado pelo DUT chegue ao medidor de maneira fidedigna, é necessário que as impedâncias estejam "casadas" para que esse sinal seja mensurado com a sua máxima potência [2].

Para averiguar o funcionamento dessa LISN, foi realizada a simulação da impedância para a faixa de frequência estudada, vista pelos terminais do medidor. O esquema utilizado para simulação no Simulink está apresentado na Figura 5 abaixo:

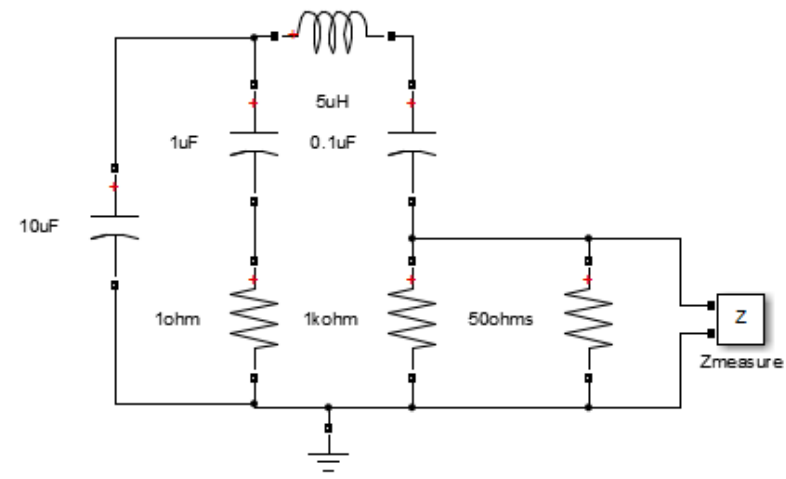

Figura 5: Circuito para estudo do comportamento da impedância no domínio da frequência vista dos terminais do medidor (Zmeasure).

O capacitor de $10 \mu \mathrm{F}$ é colocado obrigatoriamente entre os terminais da fonte para ser feita uma calibração de acordo com os parâmetros do DO-160 ou DEF-STAN-59 [6].

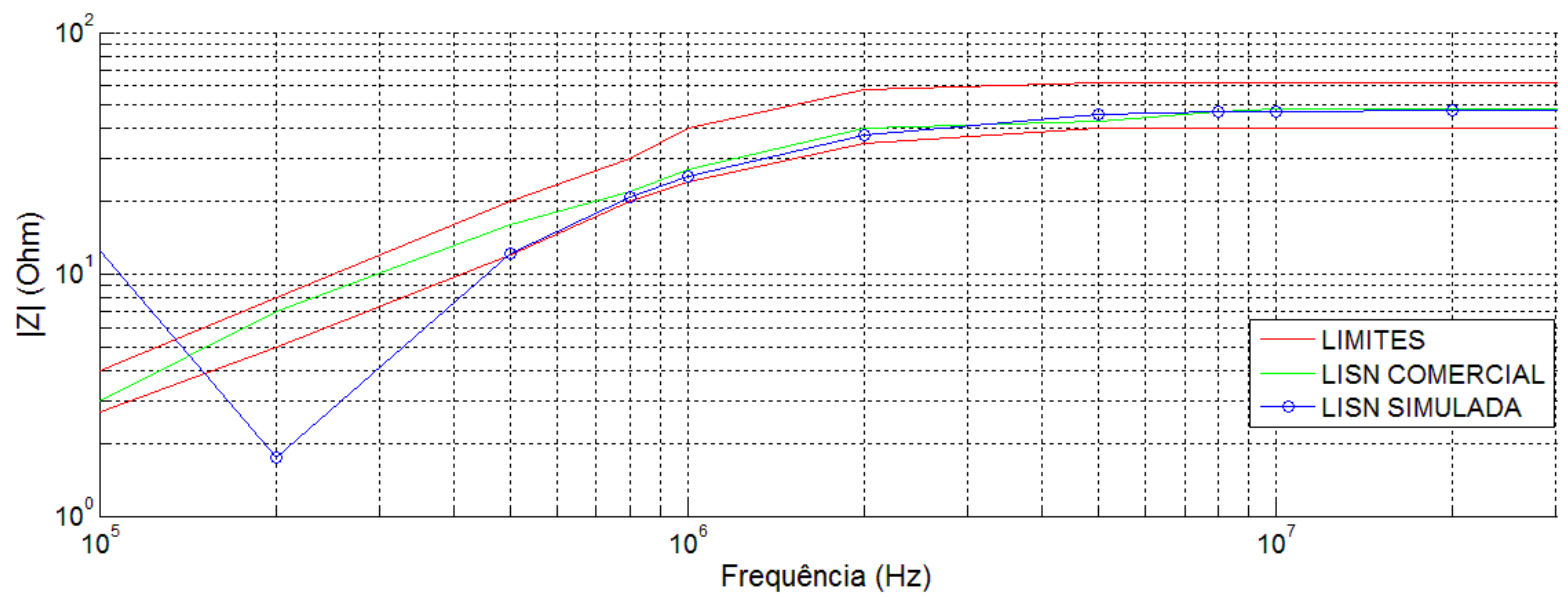

Figura 6: Gráfico da impedância vista dos terminais do medidor.

\subsection{Simulação da Transmissão do Ruído do DUT para o Medidor}

É importante que a LISN venha a prover uma transmissão sem atenuação na amplitude do ruído de alta frequência gerado pelo DUT possibilitando uma medição fidedigna [2]. 
Para verificar esse comportamento da LISN, utilizou-se as técnicas da Transformada de Laplace para o cálculo da função de transferência. A qual descreve essa transmissão do ruído em alta frequência. Os cálculos são apresentados nas equações (1) e (2). As variáveis são mostradas no esquema da Figura 7 abaixo:

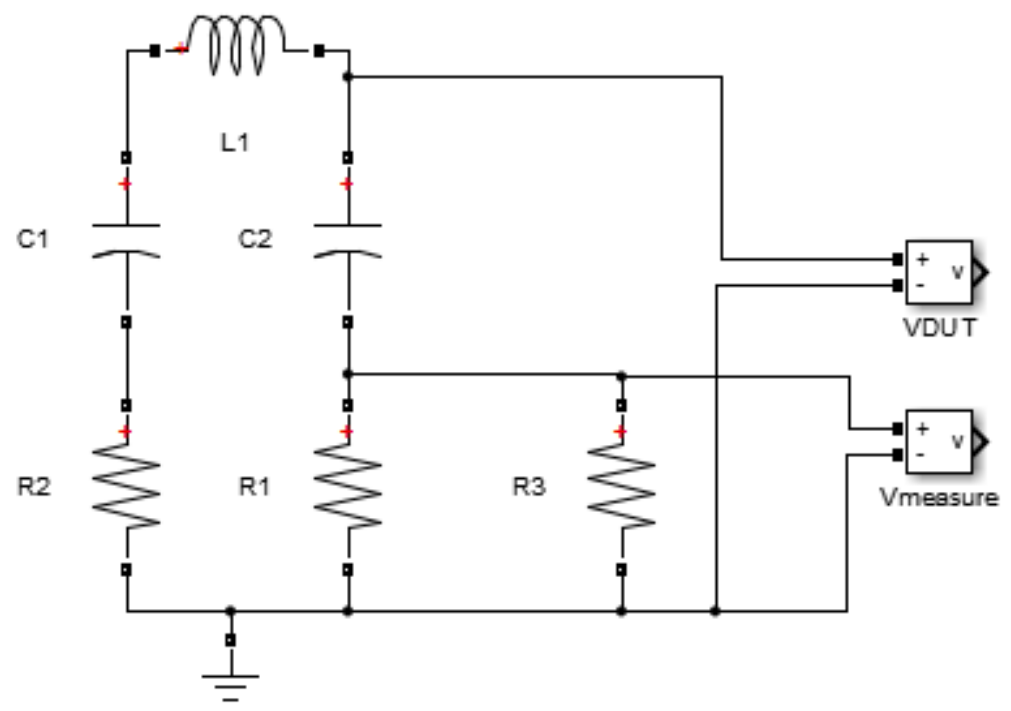

Figura 7: Esquema indicando os componentes da LISN e as variáveis relativas à formação da equação.

Foi modelada uma função de transferência $V \operatorname{div}(s)$ que caracteriza a razão entre a tensão de ruído medida pela tensão de ruído gerada pelo DUT, como mostra a equação (1):

$$
\operatorname{Vdiv}(s)=\frac{V_{\text {measure }}(s)}{V_{D U T}(s)}=\frac{R_{1} \| R_{3}}{R_{1} \| R_{\mathrm{a}}+\frac{1}{s C_{2}}}
$$

Simplificando a equação (1) acima obtém-se a seguinte função de transferência:

$$
\operatorname{Vdiv}(s)=\frac{s C_{2} R_{1} R_{3}}{s C_{2} R_{1} R_{3}+\left(R_{1}+R_{3}\right)}
$$

Através do software Matlab foi implementada a função de transferência e plotado o diagrama de Bode, a fim de apresentar a transmissão do ruído em dB. Abaixo, código utilizado:

\%Simulação - LISN Schwarzbeck NNBM 8124 - Transmissão do Ruido $\%$ Valores dos Componentes

$$
\begin{aligned}
& \mathrm{L} 1=5 * 10^{\wedge}-6 ; \\
& \mathrm{C} 1=1 * 10^{\wedge}-6 ; \\
& \mathrm{C} 2=1 * 10^{\wedge}-7 ; \\
& \mathrm{R} 1=1^{*} 10^{\wedge} 3 ; \\
& \mathrm{R} 2=1 ; \\
& \mathrm{R} 3=50 ; \\
& \% \text { Cálculo da Impedância Equivalente para a entrada da medição }
\end{aligned}
$$$$
\text { Vdiv }=\mathrm{tf}([\mathrm{C} 2 * \mathrm{R} 1 * \mathrm{R} 30],[\mathrm{C} 2 * \mathrm{R} 1 * \mathrm{R} 3 \mathrm{R} 1+\mathrm{R} 3]) \text {; }
$$$$
\text { \%Plotando o gráfico da Transmissão de Ruido }
$$$$
\text { opts }=\text { bodeoptions('cstprefs'); }
$$ 
opts.PhaseVisible = 'off';

opts.FreqUnits = 'Hz';

bodeplot(Vdiv,opts);

$x \lim \left(\left[10^{\wedge} 51.5^{*} 10^{\wedge} 8\right]\right)$;

Plotou-se o gráfico comparativo entre o comportamento dessa transmissão de ruído através da LISN simulada e comparando com a LISN comercial, como mostrado na Figura 8:

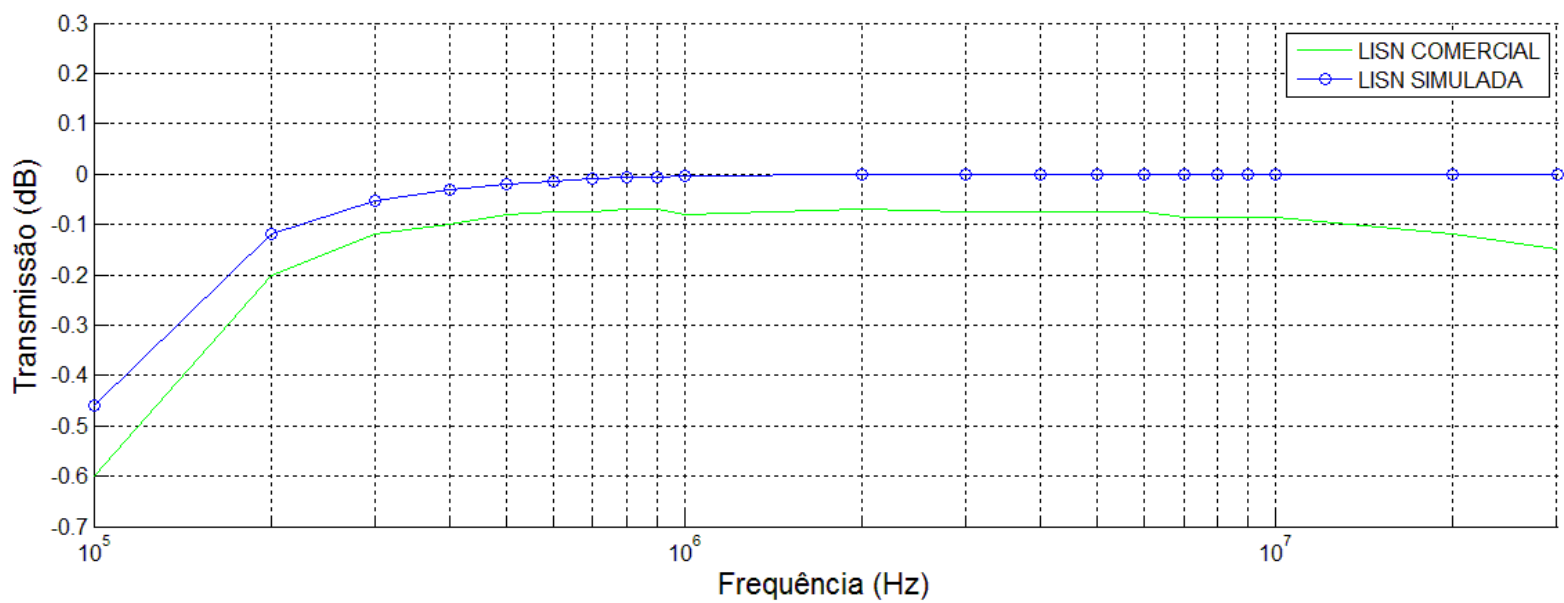

Figura 8: Gráfico da transmissão do ruído do DUT para o medidor (em dB) comparando a LISN comercial e a LISN simulada.

A razão entre a tensão nos terminais do medidor e entre os terminais do DUT, no domínio da frequência, mostra um comportamento da LISN simulada próximo ao ideal. A transmissão do sinal de ruído de alta frequência gerado pelo EUT é entregue, praticamente, sem perdas para o medidor. Tal comportamento pode ser explicado pela equação 3, ou seja, a reatância capacitiva decresce à medida que a frequência (f) aumenta.

$$
X_{C 2}=\frac{1}{2 * \pi * f * C_{2}}
$$

\section{ANÁLISE DOS RESULTADOS}

É possível observar que o comportamento da impedância da LISN com relação à frequência vista dos terminais do DUT é bem próximo da simulação tanto na magnitude quanto na fase da impedância, além disso está de acordo com as normas CISPR 16 e CISPR 25.

Em relação à curva de impedância no domínio da frequência vista pelos terminais do medidor, a simulação mostrou um bom resultado apenas a partir da frequência de $1 \mathrm{MHz}$. O que mostra que a modelagem computacional não reproduz integramente todo o comportamento da LISN comercial. Diante deste cenário é aplicável somente a uma determinada faixa de frequência de $1 \mathrm{MHz}$ a $30 \mathrm{MHz}$.

Com relação à amplitude do ruído gerado pelo DUT e transmitido para o medidor é importante salientar que os componentes utilizados na simulação são ideais. A amplitude do ruído de alta frequência produzido pelo DUT foi transmitida completamente para o medidor. Isso não acontece na LISN comercial, que a partir de certa frequência, os componentes 
começam a funcionar como circuitos RLC, que levam a uma atenuação maior do sinal de ruído, sendo isso um fator importante a ser considerado. Na LISN real, os componentes apresentam tolerâncias, as quais não são consideradas na simulação.

\section{CONCLUSÃO}

A partir dessa modelagem computacional é possível observar que os fenômenos em alta frequência mostram-se ser complexos para serem simulados computacionalmente, principalmente devido aos componentes não apresentarem um comportamento ideal e o ambiente ao qual ele é estudado não ser completamente livre de ruídos externos.

Observa-se em algumas faixas de frequência simuladas, $150 \mathrm{kHz}$ a $30 \mathrm{MHz}$, que o modelo computacional apresenta resultado muito próximo da LISN comercial, mas conclui-se que é necessário uma modelagem computacional que represente de forma cada vez mais fidedigna os fenômenos relativos a uma LISN real em toda a sua faixa de frequência. Há necessidade de aperfeiçoar a modelagem principalmente para satisfazer ao quesito da impedância vista pelos terminais do medidor.

\section{REFERÊNCIAS}

[1] Santos, K. M. G., Colin, A., Ramdani, M., Paulino, J. O. S. et al., Measure of the shielding effectiveness in coaxial cables. Amsterdam. V. 1, p. 540-548, IOS Press: ISSN: 1383-728, 2010.

[2] RYBAK, T. STEFFKA, M. Automotive Electromagnetic Compatibility (EMC). Kluwer Academic Publishers. New York, 2004.

[3] PAUL, C. R., Introduction to Electromagnetic Compatibility, Department of Electrical Engineering - University of Kentucky, Lexington. A Wiley-Interscience Publication. 2. Ed. 2006.

[4] OTT, Henry. Electromagnetic Compatibility Engineering. John Wiley \& Sons, Inc. Hoboken, New Jersey. 2009.

[5] MATHWORKS. Simulink: Dinamic System Simulation for Matlab. The Mathworks Inc, 1999.

[6] SCHWARZBECK. Datasheet: LISN NNBM 8124. Rev. http://www.schwarzbeck.de/Datenblatt/k8124.pdf Acesso em: 21 de fevereiro de 2015. 